\title{
NECROLÓGICA DEL PROFESOR JOSÉ ANTONIO SOUTO PAZ
}

\author{
José Ramón Polo Sabau \\ Catedrático de Derecho Eclesiástico del Estado \\ Facultad de Derecho \\ Universidad de Málaga \\ jpolo@uma.es
}

Escribo estas líneas, seguramente las más difíciles que haya tenido que escribir nunca, todavía bajo la honda conmoción y la gran sensación de vacío que me ha dejado la pérdida, hace tan sólo unos días, del que para mí fue mucho más que un maestro y mentor, el profesor José Antonio Souto Paz.

Desde luego no es en absoluto una tarea sencilla la de resumir en unas pocas páginas lo que fue toda una vida dedicada a la política, a la universidad y, por supuesto, a su extensa familia, y esa dificultad se me antoja aún mayor ante la sospecha de que nada de lo que pueda yo ahora reflejar aquí de manera solo esbozada podrá hacer verdadera justicia a la enorme talla intelectual y, sobre todo, humana de quien acaba de dejarnos.

En este caso la semblanza debe necesariamente dar comienzo recordando el tiempo en el que un todavía muy joven José Antonio, una vez transcurrida la primera etapa de su carrera universitaria inicialmente desarrollada junto al que fuese su tan querido maestro el profesor Pedro Lombardía, dio exitosamente el salto a la política municipal y se convirtió en el primer alcalde de la naciente democracia en la bellísima ciudad de Santiago de Compostela, donde con brillantez había obtenido su cátedra de Derecho canónico y había sido elegido decano de la Facultad de Derecho, realizando en aquellos tiempos convulsos una labor que, tal vez, en lo fundamental, se podría resumir en el titular de uno de los muchos artículos laudatorios aparecidos estos días en la prensa gallega con ocasión de su fallecimiento y en el que se le tilda, con gran acierto, de «alcalde de consenso». Porque, en efecto, mi maestro era una persona sensata, moderada y conciliadora que muy pronto hizo del diálogo y la búsqueda del consenso la seña de identidad de su actividad política, algo de lo que dan fe los numerosos testimonios que ya han aparecido también en la prensa regional 
de muchos de aquellos que, aun profesando ideologías muy distintas y perteneciendo a formaciones aparentemente tan opuestas o incluso incompatibles entre sí, fueron, no obstante, llamados por Souto Paz a formar parte como concejales de aquella primera corporación democrática, en la convicción de que solo el esfuerzo conjunto y la implicación de todos podría llevar a buen puerto la difícil tarea de transformación y adaptación al cambio social y político que por entonces estaba produciéndose en nuestro país. Aunque a quienes le hemos conocido no nos extrañe en absoluto, es verdaderamente llamativo el respeto y el afecto con el que aquellos concejales, sin excepción, provenientes de partidos tan diferentes, recuerdan estos días públicamente a aquel joven y comprometido alcalde, tal y como por cierto ya lo hicieron hace no muchos años cuando el ayuntamiento de Santiago, reconociendo esos mismos méritos y la honda huella que su paso por el Palacio de Rajoy había dejado en la historia local, decidió conceder su nombre a una calle de la ciudad; ocasión en la que, como decía, ya afloraron todas esas públicas muestras de afecto y consideración de las que, entonces sí, pudo ser testigo José Antonio con emoción, pero al mismo tiempo con la humildad que siempre le caracterizaron.

Ya establecido en la Villa y Corte tras su dimisión como primer edil compostelano - asimismo, esta última un raro ejemplo de dignidad personal y decencia política por razones que ahora no hace al caso relatar-, junto a otros aspectos tales como su participación como vocal en una Comisión del Consejo de Europa o su condición de asesor de educación y cultura del Defensor del Pueblo, su posterior trayectoria política estuvo especialmente marcada por su elección como diputado en el Congreso en la IV Legislatura, tras haberse presentado por las listas del Centro Democrático y Social. Quienes coincidieron con él en aquella etapa a buen seguro no dudarían en dar fe de la intensa actividad parlamentaria de aquel diputado centrista especialmente capaz y trabajador, que con incansable dedicación ponía siempre su sólida formación jurídica al servicio de la mejor política democrática, entendida esta, tal y como él lo hacía, como el permanente ejercicio del diálogo leal y respetuoso entre adversarios, que no enemigos, y como la insistente búsqueda de acuerdos siempre en beneficio de los ciudadanos, de su bienestar y de sus derechos. Porque mi maestro era, quizá por encima de todo y, nuevamente, como se están encargando de resaltar estos días quienes glosan su figura en la prensa con motivo de su fallecimiento, un verdadero demócrata, una persona comprometida con la libertad y con las libertades del individuo, con la defensa activa de los derechos y las garantías que trajo consigo el Estado consti- 
tucional y con los valores que este representa en su conjunto, incluyendo, claro está, el valor de la igualdad. De todo ello había dado ya una muestra inequívoca cuando, en el transcurso del fallido golpe militar del 23F, se mantuvo firme en la defensa de la Constitución y de las instituciones democráticas, adoptando de inmediato las medidas necesarias para conservar el legítimo poder civil en la ciudad y convocando a todos sus concejales a permanecer unidos frente a la asonada en la sede del ayuntamiento, mientras otros muchos, en actitud por otra parte comprensible ante lo incierto y peligroso de la situación, optaron por huir a Portugal o por esconderse en previsión de lo que pudiera acontecer. Y esa misma actitud de profundo compromiso cívico y democrático con los valores constitucionales y, en especial, con la defensa de los derechos fundamentales se dejaría traslucir también, más tarde, en su labor en las Cortes, en su actuación en las comisiones de las que formó parte, en sus enmiendas y preguntas o en sus intervenciones en el Pleno al hilo de la tramitación de unas u otras leyes. Por mi parte, pude ser testigo directo desde las bancadas de invitados del Congreso de una de aquellas intervenciones, concretamente la realizada con ocasión del debate suscitado por la Ley sobre Protección de la Seguridad Ciudadana - la comúnmente conocida como Ley Corcuera- sobre la que José Antonio, muy crítico con lo que él consideraba una vulneración por esa norma de algunas de las garantías básicas en materia de derechos fundamentales, pronunció un discurso memorable que constituyó toda una lección de teoría constitucional, como fácilmente podrá constatar quien tenga la curiosidad de acudir a las actas de aquellos encendidos debates parlamentarios.

Pero quienes tuvimos la fortuna de conocerle y, singularmente, quienes gozamos del privilegio de haber podido formarnos junto a él como juristas, sabemos bien que la vocación política de José Antonio, con ser mucha, no superaba en intensidad a su gran vocación universitaria.

En este terreno mi maestro hizo siempre gala de esa misma actitud dialogante y conciliadora, y, sobre todo, de ese mismo talante abierto, profundamente liberal y comprometido con la defensa a ultranza del pensamiento crítico y de la libertad intelectual y académica. Jamás recibí de él —y creo no equivocarme si afirmo que el resto de sus discípulos pueden decir lo mismo- ningún tipo de consigna o de imposición, en uno u otro sentido, a la hora de desarrollar mis investigaciones, cosa que pude hacer contando siempre con su consejo y con su orientación científica cuando fueron requeridos, pero al mismo tiempo con una total y absoluta libertad. José Antonio era, en este sentido como en tantos otros, la antítesis del sectarismo. 
Tras su largo paso de una década por la UNED, donde me consta que dejó un muy grato recuerdo entre los colegas de la suya y de muchas otras disciplinas, a principios de los años noventa del pasado siglo José Antonio recaló en la Universidad Complutense, donde terminaría sucediendo al profesor Navarro Valls en la dirección del Departamento de Derecho Eclesiástico del Estado de su Facultad de Derecho. Eran los tiempos en los que esta institución hacía todavía honor a una cierta tradición de ser, por su muy merecido prestigio, como solía decirse una auténtica stazione termini en la trayectoria académica de muchos de los grandes juristas habidos en nuestro país, en el sentido de que a ella acudían frecuentemente los más reputados maestros del Derecho a modo de honroso colofón a sus brillantes carreras universitarias. Ese fenómeno general se proyectaba por entonces, en particular, sobre el Departamento en el que yo inicié mi formación doctoral bajo la batuta de Souto Paz, un Departamento caracterizado en aquel momento por su notable pluralidad al estar en él representadas buena parte de las grandes escuelas del Derecho eclesiástico español con sus respectivos maestros al frente, algo que sin duda contribuyó a la enorme reputación científica y académica en aquel entonces de un centro que en muchos aspectos constituía un referente de primer orden entre la comunidad jurídica y no sólo en nuestro país. Guardo un recuerdo imborrable de aquellos años de formación en un entorno académico que era sin duda excepcional, en el que la confluencia de diferentes escuelas y perspectivas científicas en una misma sede y la convivencia diaria con los grandes maestros generaron en mí - y creo que en muchos otros - un sano espíritu de emulación y la conciencia de formar parte de un Departamento en el que el muy alto nivel jurídico de sus miembros nos obligaba a todos y en todo momento a realizar, si cabe, todavía un mayor esfuerzo en el estudio y la investigación para tratar de estar a la altura de lo que se exigía de nosotros. A todo ello contribuyó José Antonio de una manera decidida desde la dirección del Departamento, fomentando siempre esa pluralidad y ese debate científicos en lo que de él dependió e impulsando, entre otras iniciativas, la creación de un seminario de profesores en el que además quiso dar un especial protagonismo a los docentes más jóvenes, en la convicción de que ello les sería de ayuda a la hora de adquirir experiencia en estas lides — en mi caso puedo decir que así fue-.

José Antonio Souto culminó su carrera hace ya algunos años en la Facultad de Derecho de la Complutense, allí donde llegada la hora de su jubilación había desempeñado distintas responsabilidades además de la mencionada dirección del Departamento, pues fue durante un tiempo 
vicedecano, amén de director de la revista Foro en la que ahora aparece esta breve semblanza. Sé bien que esto último constituía para él un especial timbre de honor y a esa tarea le dedicó no pocos esfuerzos y una buena dosis de ilusión, apoyado en un equipo de jóvenes colaboradores que él me ponderaba siempre como excelente y de una admirable dedicación.

Mi maestro deja, como es notorio, una muy extensa obra científica que concierne a facetas muy diversas del cultivo de nuestro Derecho, sin olvidar, claro está, sus iniciales aportaciones al estudio del Derecho canónico. Dadas las características de esta nota no ha lugar a entrar aquí en pormenores a este respecto, y además se trata de una producción científica ampliamente difundida y bien conocida, pero quizá deba subrayarse la que, a mi juicio, constituye una de sus contribuciones más relevantes en las últimas décadas, como es la que representan en su conjunto todos aquellos trabajos con los que José Antonio pretendió, de uno u otro modo, revisar y proponer toda una auténtica reconstrucción de un sector normativo, el del régimen de la libertad religiosa y de las relaciones Iglesia-Estado, a su juicio inadecuadamente desarrollado en nuestra legislación vigente y lastrado, ya desde su regulación constitucional, por el peso de una serie de factores y condicionantes extrajurídicos estrechamente ligados a nuestra herencia como Estado tradicionalmente confesional. En este contexto y al hilo de su preconcepción acerca de la falta de especificidad iusfundamental de la libertad religiosa —que explica la adopción como el eje de sus planteamientos de la noción genérica de la libertad de creencias- y de su convicción de que buena parte de las bases sobre las que había venido siendo concebido y desarrollado el Derecho eclesiástico español resultaban, en muchos aspectos, constitucionalmente inadecuadas, fue paulatinamente poniendo en cuestión numerosos aspectos concernientes, por ejemplo, al desarrollo normativo especial entre nosotros de la libertad religiosa, al estatuto de las confesiones religiosas — que él consideraba habían de ser tenidas por asociaciones de relevancia constitucional en nuestro ordenamiento-, a la palmaria desigualdad existente en nuestra legislación entre quienes profesan unas $\mathrm{u}$ otras creencias religiosas en lo atinente al ejercicio de ciertos derechos y facultades, etc. José Antonio terció en el por momentos efervescente debate científico suscitado a propósito de todos estos temas a menudo con posiciones muy críticas e incisivas y sin rehuir nunca la confrontación dialéctica cuando creyó que era necesario, pero, como era propio de su talante, lo hizo siempre con respeto y con exquisita cortesía, sin menospreciar a nadie y dejando siempre muestra de su proverbial espíritu de concordia. 
Su desaparición — que para algunos de nosotros lo es sólo física, pues estará siempre en nuestro recuerdo y en nuestros corazones- impedirá que vean la luz algunos de los proyectos científicos, de una u otra índole, de los que me habló en alguna ocasión y que ya en los últimos años la enfermedad había convertido en improbables, y, asimismo, su ausencia hará que uno no pueda ya seguir tratando de convencerle de que lleve a término algunos otros empeños que siempre creí merecía la pena que realizase, pero para los que, por unas u otras razones, nunca encontró el tiempo o la oportunidad adecuados. Se queda, pues, sin escribir, por ejemplo y pese a que tantas veces traté de persuadirlo para ello, la tan poco edificante historia del abrupto final que experimentó la célebre Escuela de Navarra, aquella excepcional experiencia científica y académica desarrollada allá por los años sesenta del siglo xx en torno a la no menos excepcional figura de Pedro Lombardía, cuyo desenlace resulta tan triste como aleccionador; tengo para mí que José Antonio se resistía a dar público testimonio de aquella peripecia, o al menos a hacerlo por escrito, sobre todo por su voluntad de no desairar o ni tan siquiera incomodar a algunos tan queridos y viejos amigos que de una u otra forma se vieron involucrados en ella, pues ese tacto y esa consideración eran también seña de identidad de mi maestro, y, si tal fue el caso, quizás haya sido mejor así.

Todo esto es en alguna medida importante, pero evidentemente no lo es tanto, ni mucho menos, como lo es en sí misma la pérdida del mentor, del maestro y amigo, de la persona de tan extraordinaria calidad humana que sin duda nos hizo mejores a quienes tuvimos la fortuna de recorrer junto a él un trecho del camino. De él aprendí muchas cosas, pero las más importantes no tienen que ver con el Derecho o con la academia; José Antonio enseñaba con el ejemplo y con su rectitud de conducta, con sus firmes convicciones democráticas y con su inquebrantable amor por la libertad. Fue un hombre bueno - en el buen sentido de la palabra, bueno, como diría Machado- y fue también un hombre libre, y ese ejemplo es acaso el principal legado que nos deja a quienes tanto le quisimos y ya tanto le echamos de menos. Descansa en paz maestro. 